\title{
Religiosity, crime and drug use among juvenile offenders
}

Sung Joon Jang is Research Professor of Criminology and Co-director of the Program on Prosocial Behavior at Religition at Baylor University. Religion at Baylor University effects of religion on crimin offending and desistance and the rehabilitative effects of faith-based programmes on prisoners. Here, we take a closer look at Dr Jang's research, which demonstrates that individuals who experience a fast increase in religiosity are decrease in crime/drug use (i.e. desistance) or a slow increase (i.e. deceleration).

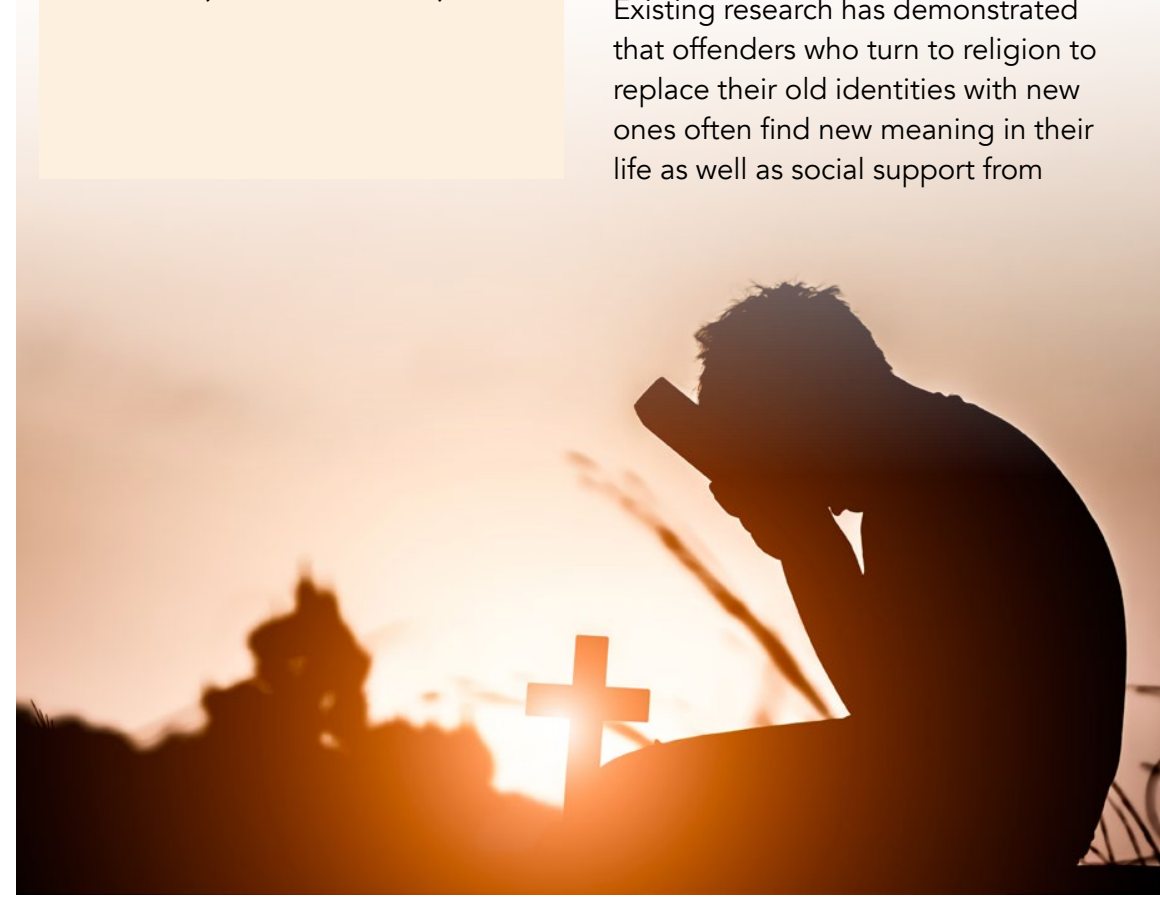

coreligionists. This internal change and new identity stemming from religion marks the beginning of a non-criminal, procial To examine oher types an offender's involvement in religion, Dr Jang conducted his own study using longitudinal data from juvenil offenders, followed over a decade, in the United States.

\section{NOVEL APPROACH: RATES OF CHANGE IN RELIGIOSITY AND} CRIME/DRUG USE

The existing research focuses mainly on the relationship between the level of religiosity and the level of crime and drug use at a single point in time or changes in crime and drug use between two time points. For example, this means that studies typically examine religiosity at Time 1 report low levels of civios between Times 1 and 2 .

Dr Jang's study draws on prior research and expands on it by focusing on rates of change in religiosity and crime/drug use over more than two time points. Furthermore, Dr Jang's research examines rates of change in used to measure internal changes, in order to provide insight into religiosity's relationship with crime and drug use: moral disengagement, legal cynicism, impulse control, and suppression of aggression. The first two variables have rarely been tested despite their relevance to the explanation of crim
and drug use, whereas the others

re measures of self-control. These psychosocial variables are expected drug use relationship (ie. explain the effect of religiosity (i.e. explain the use) because religiosity is likely to be associated inversely with moral disengagement and legal cynicism and positively with impulse control and suppression of aggression, whereas the former (moral disengagement and legal cynicism) and latter variables (impulse control and suppression of aggression) are likely to be related to crime/ drug use in the positive and negative direction, respectively.

In sum, Dr Jang hypothesises that individuals who experience a fast increase in rligiosity are expected to (ie desist decer or sowinge/dng use (i.e. desistance) or

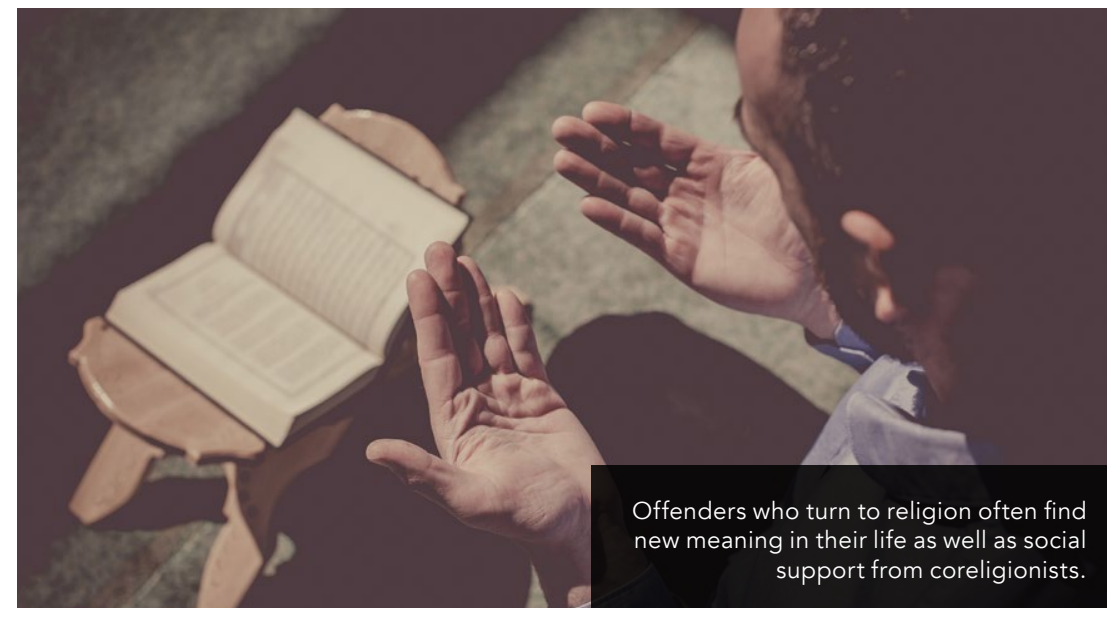

(which makes it possible to estimate relationship between rates of change in variables over time) to data from the Pathways to Desistance study. pa from a baseline interveed pane and drug use (i.e. inverse relationship is hypothesised to be explained partly by a fast increase in religiosity leading to a fast decrease or slow increase in moral disengagement

Religiosity

(entrol [decreased] moral disengagement and legal cynicism, which resulted in a synagogue, or other religious activities salience, experiences, and (religious salience, experiences, and efficacy). (11 aggressive and 8 income offending whereas drug use was binge drinking and marijuana use.

The study examined the above-mentioned psychosocial characteristics to decrease in crime and drug use. $\quad \begin{aligned} & \text { characteristics to } \\ & \text { provide insight } \\ & \text { into religiosity's }\end{aligned}$ and legal cynicism and a fast increas or slow decrease in impulse control and suppression of aggression, which in turn contributes to a fast decrease or slow increase in crime and drug use.

1,289 adjudicated youths $(1,121$ males and 168 females) from the juvenile and adult court systems in two counties of the United States (one in Arizon and the other in Pennsylvania) and

METHODS AND SAMPLING To test these hypotheses, Dr Jan (n) religious involvement was measured

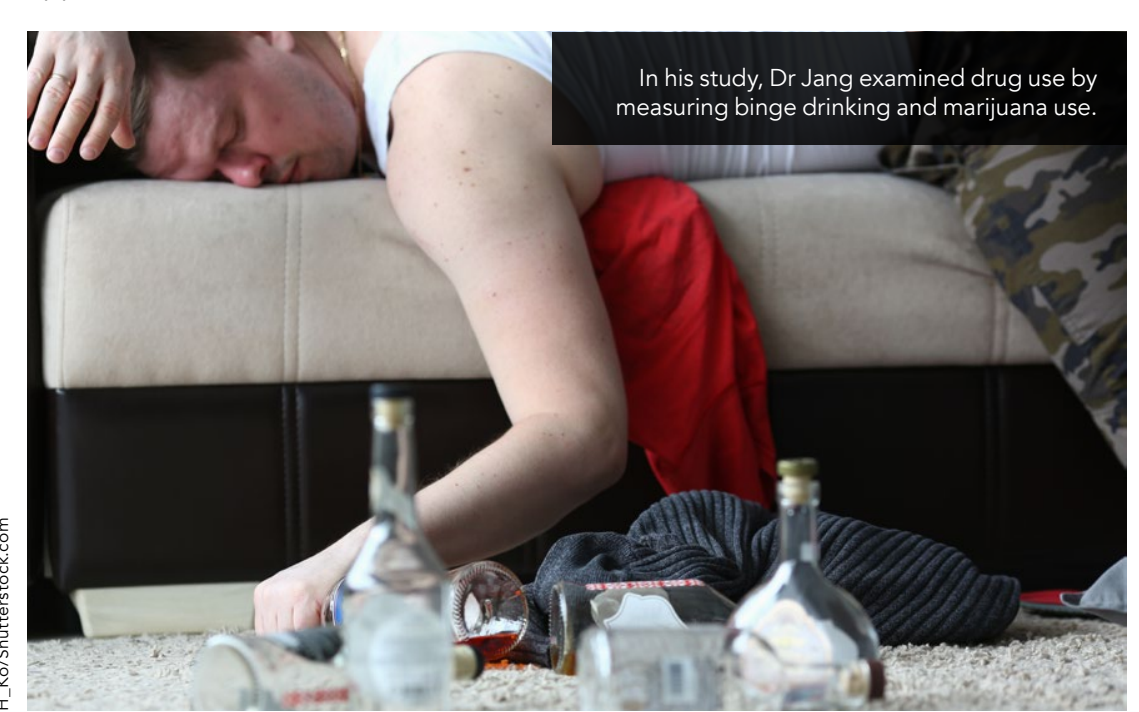

relationship with crime and drug use: moral disengagement, legal cynicism, impulse control, and suppression of aggression. These characteristics were measured by multi-item scales (taking and time-varying as woll as timeinvarine-varying as well as timefor in analysis In terms of time-varying the time is included in Dr Jang's analysis. This measures time on the street vs in secure settings, whether an institution, drug-treatment programme, or psychiatric hospital, which would affect the probability of offending and drug use. Time-invariant covariates included gender, race, age, social class and fomly structure.

The total sample included $86.6 \%$ male, $21.3 \%$ white, $43.5 \%$ black, and $35.2 \%$ Hispanic youth. A small minority (15.0\%) of study participants were living with their biological parents at the time of the baseline interview, 


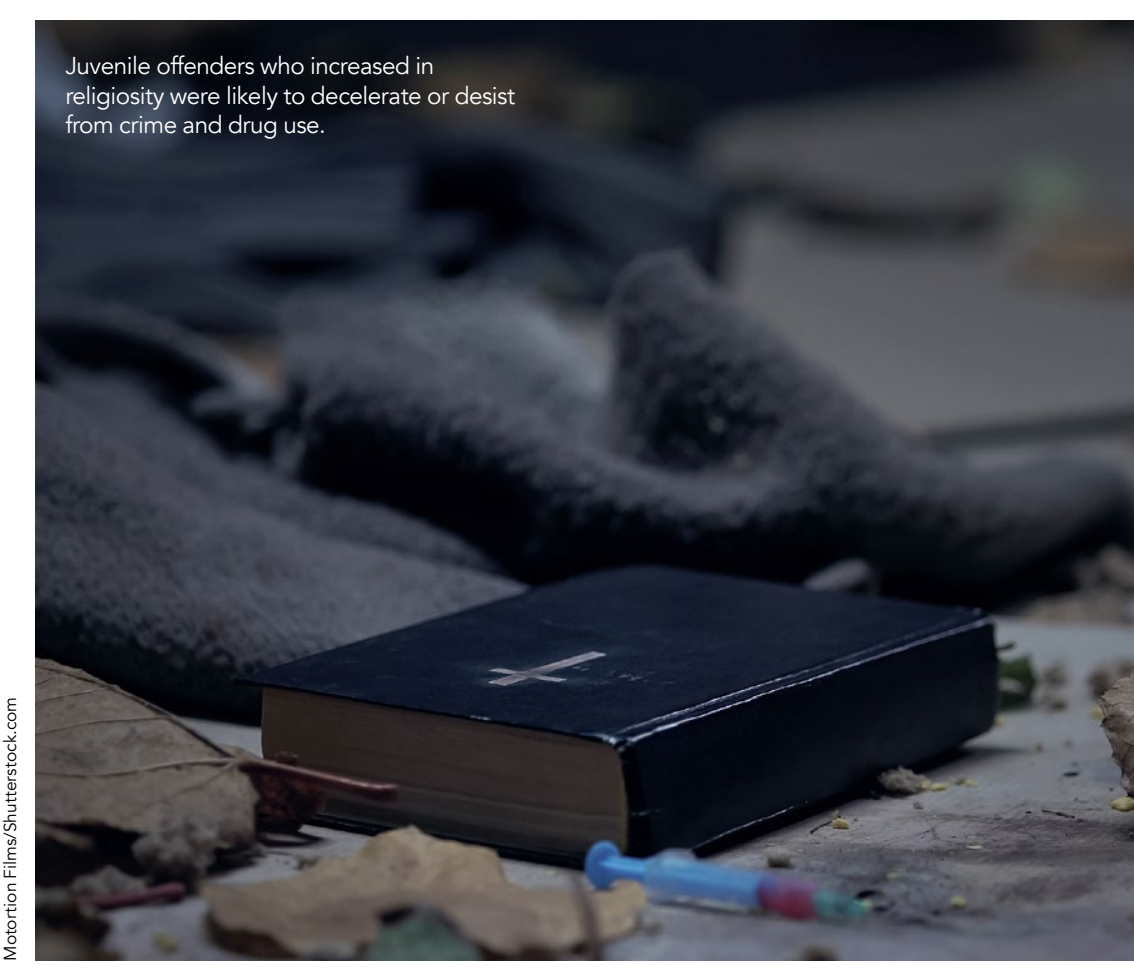

Religion needs to be seriously considered for criminal justice policy within constitutional boundaries.

average, higher than 2-year college degree or its equivalents, though less than 4-year college degree. The average age of participants at the initial interview was about 16 years old, and the last interview (\#11) was conducted when they reached (on average) age 23

\section{THE MAIN FINDINGS}

\section{Results generally supported the}

hypotheses. First, juvenile offenders likely to have their crime, marijuana use, and, to a lesser extent, binge drinking decrease fast or increase slowly. That is, juvenile offenders who increasingly attended religious activities, perceived religion to be important and helpful in their lives, and experienced God's care and love and a close personal relationship to God were likely to increase their crime/ marijuana use slowly, or decrease quickly, relative to those who did not. Second, this inverse relationship was attributable to religiosity increasing aggression and decreasing moral
PRACTICAL IMPLICATIONS: JUSTICE POUICY Religion is found to

positive behaviout to contribute to juvenile offenders by enhancing prosocial characteristics and reducing antisocial ones. These findings regarding religious influence on internal change are consistent with previous studies th show religion has rehabilitative effects on offenders by helping them replace their criminal identity with a new one (e.g. a child of God), develop a sense of meaning and purpose in life, and enhance personal virtues. The overal findings have a practical implication: religion needs to be seriously conside ed for cim inal justice policy

IMITATIONS OF THE STUDY AND SCOPE FOR FUTURE RESEARCH on the effect of religiosity on crime and drug use, the reversed effect was not examined simultaneously although reciprocal relationships between religiosity and crime/drug use are plausible (e.g. Johnson et al. 2001). Similarly, relationships between religiosity and its psychosocial correlates and those between psychosocial correlates and crime/drug use might have been bidirectional as well. For example, legal cynicism was likely to decrease religiosity, while religiosity was expected to decrease legal offend orenders, from which this study's date counties of different states and were not based on random selection. As a result, the present findings are not generalisable, even to those counties. In addition, future research needs to replicate the present study by analysing data from non-institutionalised as well as institutionalised youths to see whether the patterns of relationships are consistent with what this study found. Third, this study did not test hypothesis for gender or race/ethnic groups, so future studies need to fill this gap. Finally, besides the key variables, the participant's sociodemographic characteristics were included in the model, but could not control for other variables including ther

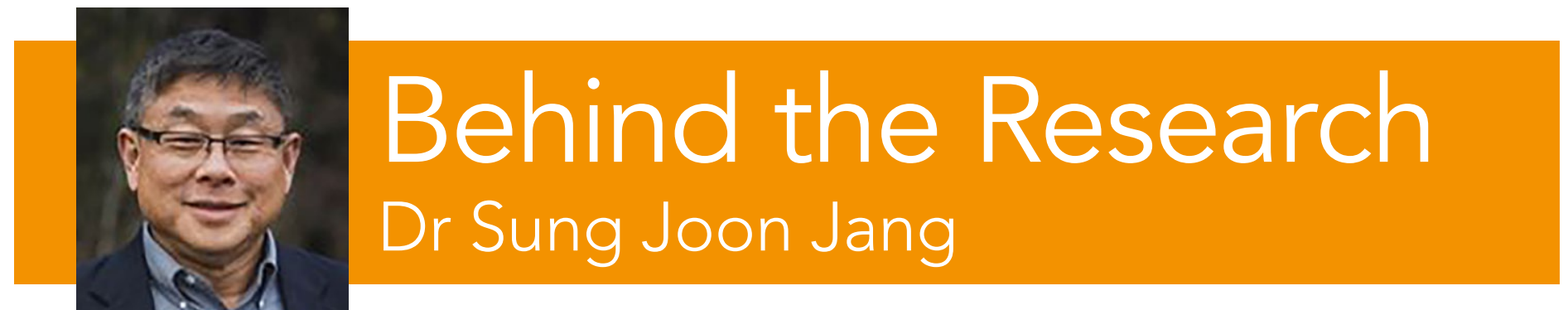

E: sung_joon_jang@baylor.edu T: $+12547101691 \quad$ W: https://www.baylorisr.org/ W: : https://www.baylorisr.org/sung-joon-jang/

\section{Research Objectives}

Dr Jang investigates the inverse relationship between the rates of change in religiosity and crime/drug use

\section{Detail}

Sung Joon Jang

Baticte for Studies of Religion

One Bear Place

Waco, Texas, 76798

USA

Bio

Sung Joon Jang is Research Professor of Criminology and Co-director of the Program on Prosocial Behavior at the Institute for Studies of Religion at Baylor University. His research focuses on the effects of religion on criminal offending and desistance and the rehabilitative effects of faith-based programmes on prisoners.

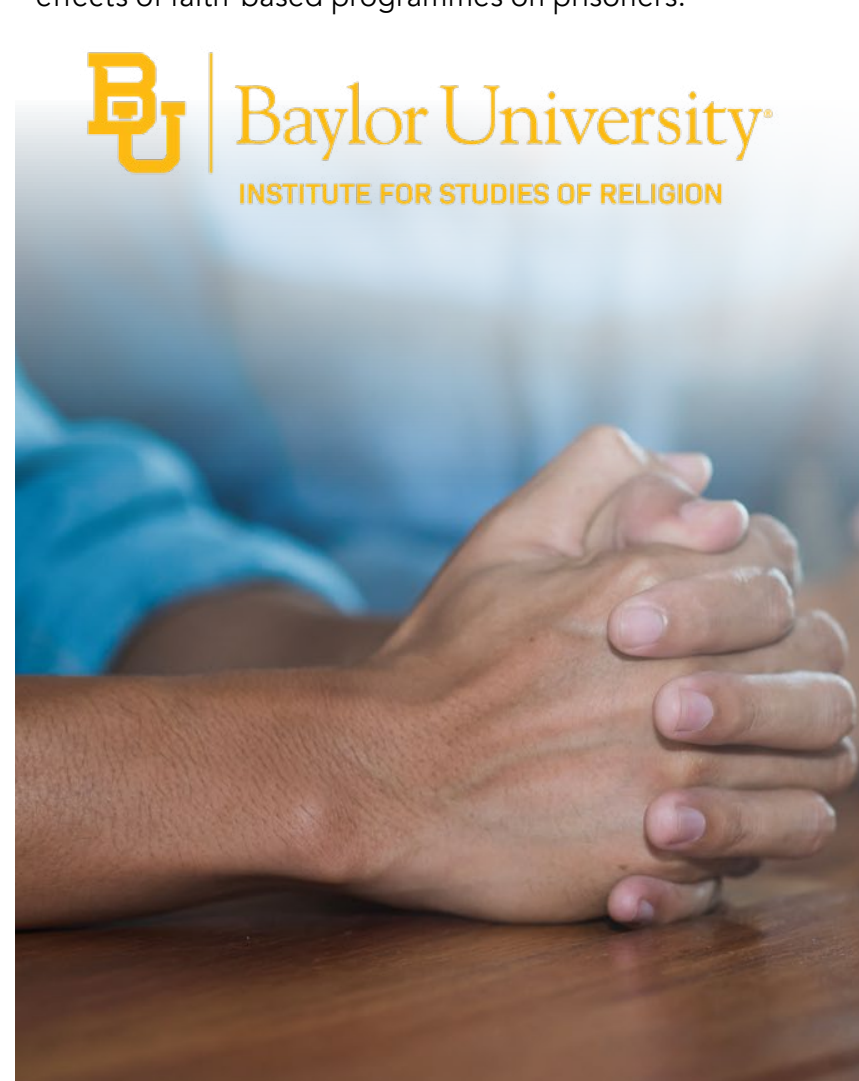

\section{References}

Jang, S.J. (2019). Religiosity, Crime, and Drug Use Among Juvenile Offenders: A Latent Growth Modeling Approach. Journal of Quantitative Criminology, 35(1), 27-60. Available at: https://www.doi.org/10.1007/s10940-0179369-2

Johnson, B.R., Jang, S.J., Larson, D.B., Li, S.D. (2001). Does adolescent religious commitment matter? A reexamination of the effects of religiosity on delinquency. Journal of Research in Crime and Delinquency, 38(1), 22-44. Available at: https://www.doi.org/10.1177/0022427 801038001002

Evans, T.D., Cullen, F.T., Dunaway, R.G. and Burton, V.S., JR. (1995). Religion and Crime Reexamined: The Impact of Religion, Secular Controls, and Social Ecology on Adult doi.org/10.1111/j.1745-9125.1995.tb01176.x

\section{Personal Response}

\section{What sparked your interest in this research?}

WI First, the inverse relationship between religiosity and
crime/drug use is well established based on samples of the general population but has been less often examined using data from offenders despite its potential policy implications. Second, prior research was based mostly used, they were collected at two or three time points. Thus, its analysis was largely correlational, not causal, and unable to estimate a long-term relationship between changes in religiosity and crime/drug use. Finally, why been understudied. This study intended to address the
limitations of prior research.

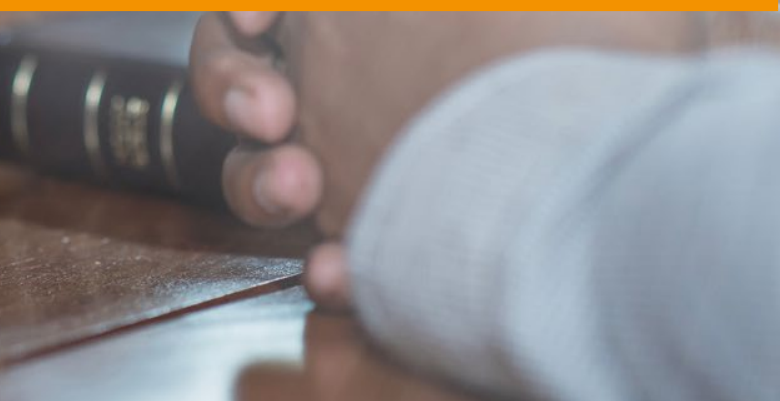

